\title{
A catalysis-driven artificial molecular pump
}

DOI:

10.1038/s41586-021-03575-3

\section{Document Version}

Accepted author manuscript

Link to publication record in Manchester Research Explorer

\section{Citation for published version (APA):}

Amano, S., Fielden, S. D. P., \& Leigh, D. A. (2021). A catalysis-driven artificial molecular pump. Nature, 594(7864), 529-534. https://doi.org/10.1038/s41586-021-03575-3

\section{Published in:}

Nature

\section{Citing this paper}

Please note that where the full-text provided on Manchester Research Explorer is the Author Accepted Manuscript or Proof version this may differ from the final Published version. If citing, it is advised that you check and use the publisher's definitive version.

\section{General rights}

Copyright and moral rights for the publications made accessible in the Research Explorer are retained by the authors and/or other copyright owners and it is a condition of accessing publications that users recognise and abide by the legal requirements associated with these rights.

\section{Takedown policy}

If you believe that this document breaches copyright please refer to the University of Manchester's Takedown Procedures [http://man.ac.uk/04Y6Bo] or contact uml.scholarlycommunications@manchester.ac.uk providing relevant details, so we can investigate your claim.

\section{OPEN ACCESS}




\title{
A Catalysis-Driven Artificial Molecular Pump
}

\author{
Shuntaro Amano ${ }^{1}$, Stephen D. P. Fielden ${ }^{1}$ and David A. Leigh ${ }^{1,2 *}$
}

${ }^{1}$ Department of Chemistry, University of Manchester, Oxford Road, Manchester M13 9PL, UK.

${ }^{2}$ School of Chemistry and Molecular Engineering, East China Normal University, 200062 Shanghai, China.

*e-mail: david.leigh@manchester.ac.uk

\section{Summary/Opening Paragraph}

All biological pumps are autonomous catalysts; they maintain the out-of-equilibrium conditions of the cell by harnessing the energy released from their catalytic decomposition of a chemical fuel. ${ }^{1-3}$ A number of artificial molecular pumps have been reported to date, ${ }^{4}$ however they are all either fueled by light ${ }^{5-10}$ or require repetitive sequential additions of reagents or varying of an electric potential during each cycle to operate ${ }^{11-16}$. Here we report on an autonomous chemicallyfueled information ratchet ${ }^{17-20}$ that in the presence of fuel continuously pumps crown ether macrocycles from bulk solution onto a molecular axle without the need for further intervention. The mechanism uses the position of a crown ether on an axle to both promote barrier attachment behind it upon threading and to suppress subsequent barrier removal until the ring has migrated to a catchment region. Tuning the dynamics of both processes ${ }^{20,21}$ enables the molecular machine ${ }^{22-25}$ to continuously pump macrocycles from their lowest energy state in bulk solution to a higher energy state on the axle. The ratchet action is experimentally demonstrated by the progressive pumping of up to three macrocycles onto the axle from bulk solution under conditions where barrier formation and removal occur continuously. The out-of-equilibrium [n]rotaxanes (characterised with $n$ up to 4 ) are maintained for as long as unreacted fuel is present, after which the rings slowly de-thread. The use of catalysis to drive artificial molecular pumps opens up new opportunities, insights and research directions at the interface of catalysis and molecular machinery.

\section{Main}

The structure and mode of operation of the catalysis-driven molecular pump, 1, is shown in Fig. 1. One end of the axle is permanently blocked by a bulky triarylmethine group (brown); the other end of the axle (the $N$-terminus) is open for threading when in the form of a benzyl amine group (orange). The axle includes a chain of triazole heterocycles linked by short, propyl $\left(-\left(\mathrm{CH}_{2}\right)_{3}-\right)$, spacers. Triazoles only 
interact weakly with crown ethers, ${ }^{26,27}$ so the proportion of crown ethers transferred from bulk solution through the open end of the axle and onto the chain is vanishingly small at equilibrium. The pumping mechanism is based on a recently discovered ${ }^{28}$ metal-free $^{29,}{ }^{30}$ active template rotaxane-forming reaction, ${ }^{31}$ in which addition of a primary amine to an electrophile is accelerated through the cavity of a crown ether. Pump 1 reacts with Fmoc- $\mathrm{OC}_{6} \mathrm{H}_{4} \mathrm{NO}_{2}$ (the fuel, ${ }^{32}$ 2; Fmoc = 9-fluorenylmethyloxycarbonyl) and 24-crown-8 (3; blue) causing active template threading of the ring, initially forming car-4 (Fig. 1 ; the italicised prefix indicates the position of the ring on the axle). The newly-formed Fmoc-carbamate group (green) prevents dethreading of the ring back over the axle $\mathrm{N}$-terminus. Adjacent to the benzyl amine group is a trifluoromethyl $\left(\mathrm{CF}_{3}\right)$ group (red), which is of sufficient size to significantly slow the passage of 24-crown-8 (a 'speed bump'9). The triazole groups on the axle should form more favourable interactions with the crown ether ${ }^{26,27}$ than the sterically-crowded benzylic carbamate in car-4, and so provide a 'catchment region' for rings threaded onto the axle. Accordingly, over time the crown ether in car-4 slowly passes over the trifluoromethyl group to the catchment region, forming co-conformer tri-4 ('co-conformers' are structures that differ in the relative positions of their components ${ }^{33}$ ). Rotaxane tri4 is of lower energy than car-4, but still of higher energy than the unthreaded components 1 and 3 . The presence of a base (diisopropylamine ( $\left.i-\mathrm{Pr}_{2} \mathrm{NH}\right)$ in Fig. 1$)$ is necessary to complete the pumping cycle. The base deprotonates the Fmoc-carbamate group, triggering its fragmentation to dibenzofulvene (5), $\mathrm{CO}_{2}$ and 4-nitrophenol $\left(\mathrm{NO}_{2} \mathrm{C}_{6} \mathrm{H}_{4} \mathrm{OH} ; 6\right)$, liberating the amine $\mathrm{N}$-terminus of the molecular machine for use in further pumping cycles. In this way, rings are captured from bulk solution, constrained within a localised region of the axle, and maintained in an out-of-equilibrium state by the continuous, autonomous, consumption of the chemical fuel. 


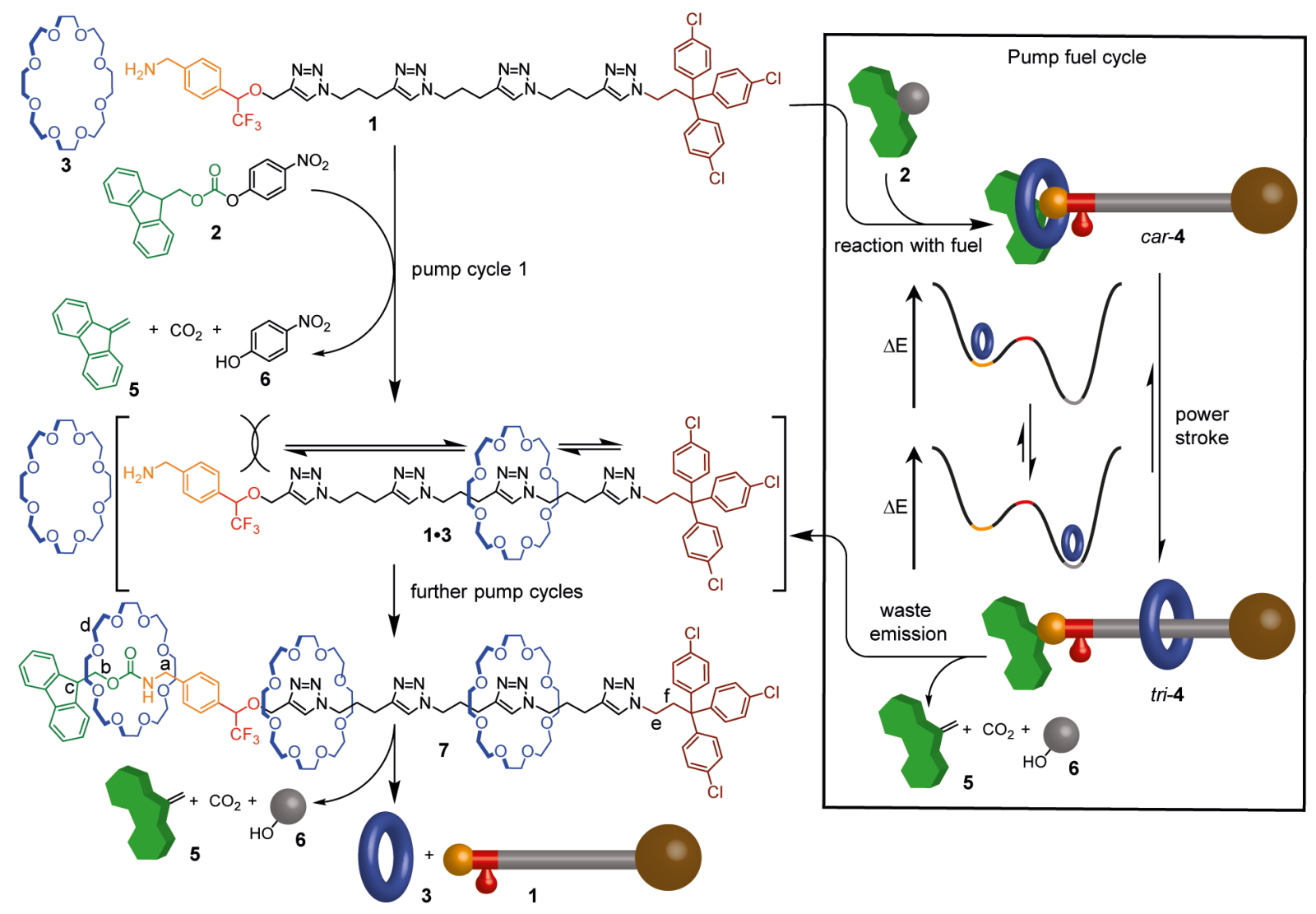

Figure 1. Structure and operation of a catalysis-driven artificial molecular pump. Continuous pumping of 24-crown-8 rings (3) onto a molecular axle (1) in the presence of fuel (2), causing the rings to be dissipatively captured in the form of [n]rotaxanes such as 7. Typical operating conditions: 1 (1 eq.), 3 (10 eq.), $i-\mathrm{Pr}_{2} \mathrm{NH}$ (15 eq.), toluene ( $0.2 \mathrm{M}$ with respect to 1 ), 2 (either $10+$ eq. added at time-zero, or added continuously via syringe pump at a rate of $0.7 \mathrm{eq} . / \mathrm{h}$ ), room temperature. Box: Pump fuel cycle. Kinetically-gated addition of the fuel to the pump causes active template threading of the ring onto the axle, initially forming rotaxane co-conformer car-4 (macrocycle positioned over the carbamate axle site). The rotaxane relaxes to the lower energy state, tri-4, through a power stroke (although in the formation of [4]rotaxane 7 from $1 \cdot(3)_{2}$ the equivalent step is not exergonic). Kinetically-gated decomposition of the blocking group (green) to waste, liberates the open end of the axle for further pumping while threaded rings remain kinetically trapped in the catchment region (grey part of the axle in the cartoon), completing the pumping cycle.

The pump and fuel structure, in particularly the stereoelectronic characteristics of the $\mathrm{CF}_{3}$ speedbump, the triazole groups of the catchment region, and the 4-nitrophenol leaving group of the fuel, were selected through a series of model and optimisation studies (Supplementary Information). The pump operating conditions (see Fig. 1) were chosen so that the Fmoc-removal reaction and the passage of the rings from the catchment region of the axle back over the $\mathrm{CF}_{3}$ group (resulting in dethreading when the pump $N$-terminus is not blocked) are both much slower than active template reaction of the axle 
benzylic amine group with unreacted $\mathrm{Fmoc}-\mathrm{OC}_{6} \mathrm{H}_{4} \mathrm{NO}_{2}$ fuel. This means the $\mathrm{N}$-terminus of $\mathbf{1 \cdot 3}$ undergoes further active template reactions before dethreading occurs, pumping a second (and subsequently third) ring onto the axle. The molecular machine continues to pump rings onto the axle for as long as there is sufficient space on the chain and unreacted fuel present.

Pump 1 was synthesised in 13 steps (see Supplementary Information) and operated successfully in three distinct ways: (i) stepwise, adding the fuel and base in separate steps, which facilitated isolation of the rotaxanes; (ii) autonomously, with all of the fuel added to the rings, pump and base at time-zero; (iii) continuous fuel addition, which minimises background decomposition of the fuel by the base. The pumping mechanism was confirmed by operating 1 in a stepwise manner. A single pumping cycle, other than removal of the Fmoc barrier, was performed by combining 1, 2 and 3 in toluene under basic conditions (Fig. 1), affording [2]rotaxane 4 in $61 \%$ yield after 10 minutes (the amount of rotaxane did not increase using longer reaction times), with concurrent formation of the Fmoc-derivatised unthreaded axle in $10 \%$ yield. This shows that $>80 \%$ of the fuel molecules (2) that react with 1 result in threading. The formation of [2]rotaxane under conditions where the release of the blocking group (waste-forming step) is negligible shows that during the fuel addition step of the pumping mechanism, the pumping is kinetically gated (i.e. threading accelerates Fmoc-carbamate formation of the axle).

The interconversion of car-4 and tri-4 is slow on the ${ }^{1} \mathrm{H}$ NMR (proton nuclear magnetic resonance spectroscopy) timescale at $295 \mathrm{~K}$ in $\mathrm{C}_{6} \mathrm{D}_{5} \mathrm{CD}_{3}$ (Fig. 2C), allowing the ratio of the [2]rotaxane coconformers to be determined. Various axle protons are deshielded by the presence of the macrocycle: in particular, $\mathrm{H}_{\mathrm{a}}, \mathrm{H}_{\mathrm{b}}$ and $\mathrm{H}_{\mathrm{c}}$ of car-4 (labelling shown in Fig. $2 \mathrm{~A}$ ), and $\mathrm{H}_{\mathrm{e}^{\prime}}$ and $\mathrm{H}_{\mathrm{f}^{\prime}}$ of tri-4. Signal integration gives a car-4:tri-4 ratio (i.e. local equilibrium distribution of a single crown ether between car- and trisites) of $3: 7$ at $295 \mathrm{~K}$ in $\mathrm{C}_{6} \mathrm{D}_{5} \mathrm{CD}_{3}$. 
A
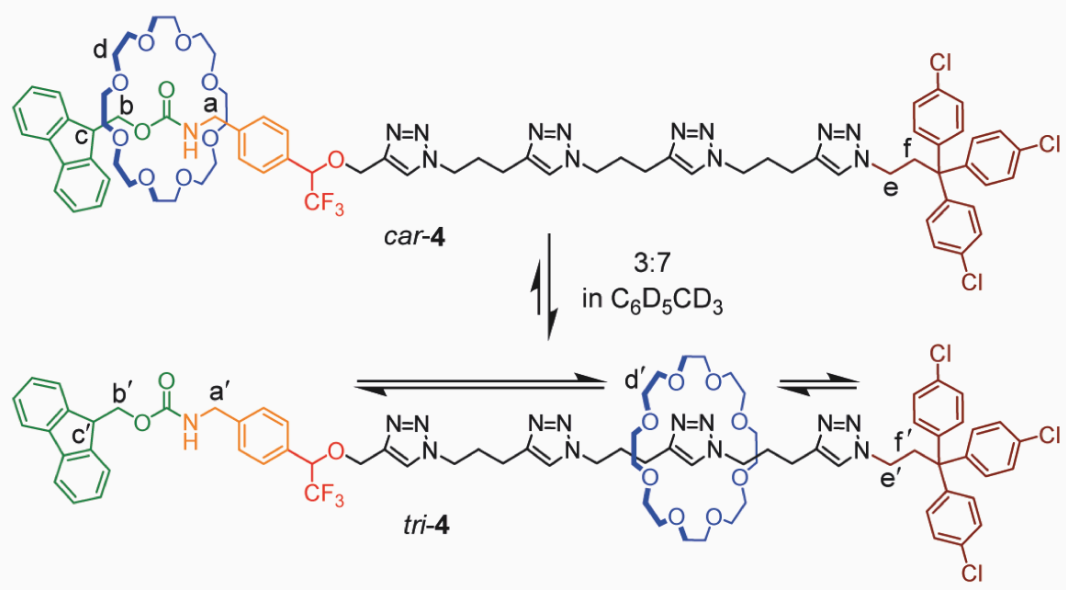

B
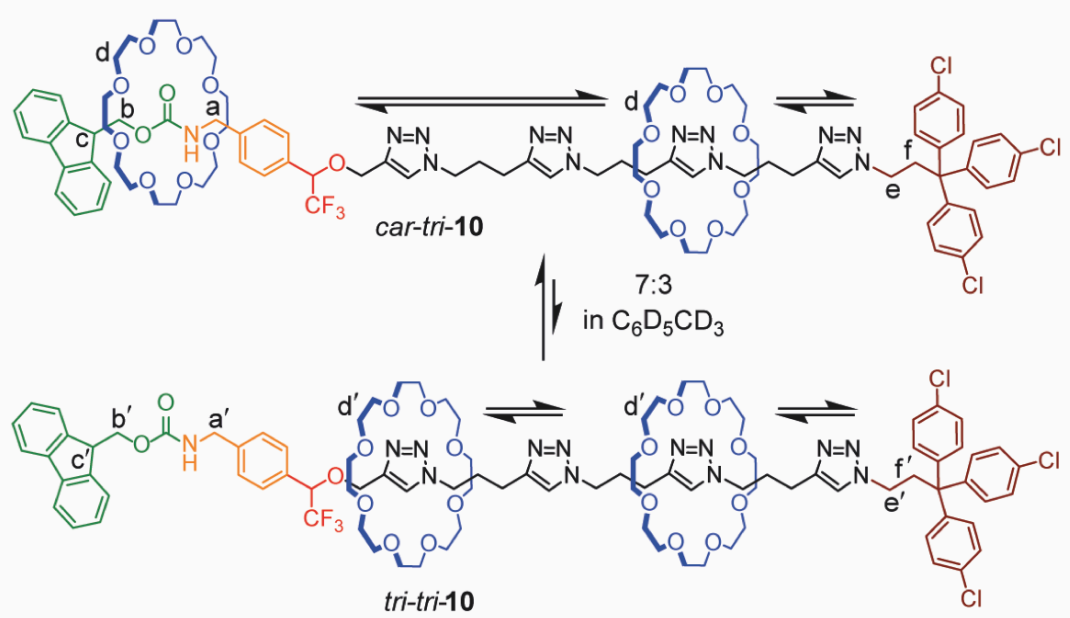

C
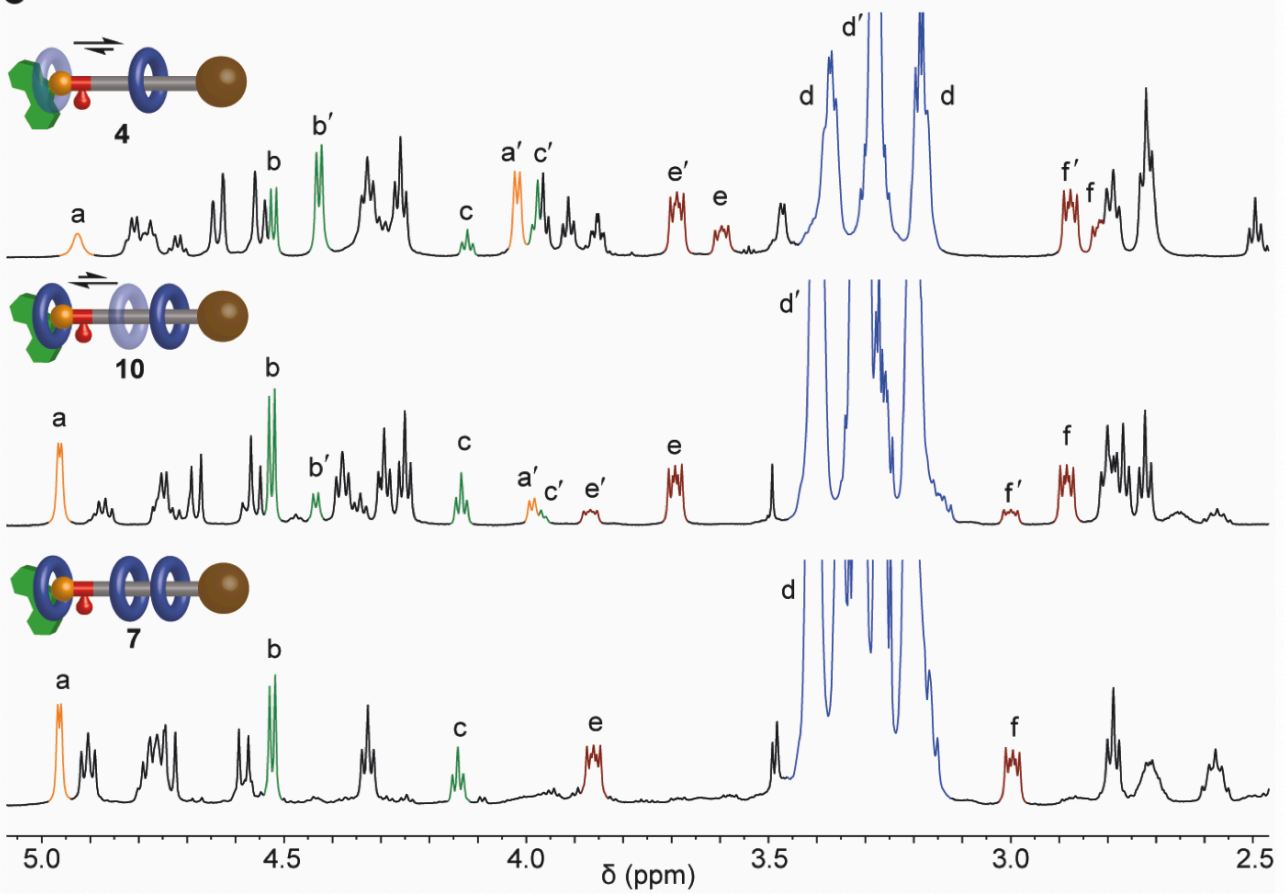

Figure 2. Macrocycle distribution in [n]rotaxane co-conformers. (A) Macrocycle positions in [2]rotaxane co-conformers car-4 and tri-4 (295 K, $\left.\mathrm{C}_{6} \mathrm{D}_{5} \mathrm{CD}_{3}\right)$. (B) Macrocycle positions in [3] rotaxane co-conformers car-tri-10 and tri-tri-10 (295 K, $\left.\mathrm{C}_{6} \mathrm{D}_{5} \mathrm{CD}_{3}\right)$. (C) Partial ${ }^{1} \mathrm{H} \mathrm{NMR}\left(600 \mathrm{MHz}, 295 \mathrm{~K}, \mathrm{C}_{6} \mathrm{D}_{5} \mathrm{CD}_{3}\right)$ spectra of 4, 10 and [4]rotaxane 7. 
To complete the pump cycle, the Fmoc group needs to be removed from the $\mathrm{N}$-terminus of 4 to regenerate the primary amine for another threading event. The position of the macrocycle on the axle significantly affects the rate of $\mathrm{Fmoc}$ removal. When treated with $i-\mathrm{Pr}_{2} \mathrm{NH}$ in toluene, the half-life of a model rotaxane, $\mathbf{8}$, which has 24 -crown-8 constrained on a short axle and forced into close proximity to the Fmoc group, was found to be $\sim 3 x$ longer than that of the corresponding non-interlocked thread 9 (Fig. 3A). During the operation of pump 1, the ring's steric inhibition of the attack of $i-\mathrm{Pr}_{2} \mathrm{NH}$ means that the Fmoc group is removed more rapidly from the $\mathrm{N}$-terminus in co-conformers where all the threaded macrocycles are in the catchment region, i.e. tri-4 and tri-tri-10 react faster than car-4 and car-tri-10, suppressing dethreading. This means that the waste removal step (the Fmoc-carbamate-to-wasteproducts reaction) is also kinetically gated in the pumping mechanism of 1 (i.e. deblocking of the $\mathrm{N}$ terminus occurs more rapidly when all of the threaded macrocycles are located in the catchment region).

Fmoc removal from 4 with the strong base 1,8-diazabicyclo[5.4.0]undec-7-ene (DBU) was complete within 30 seconds, allowing the half-life of pseudorotaxane $1 \cdot 3$ to be measured as 230 minutes in $\mathrm{C}_{6} \mathrm{D}_{5} \mathrm{CD}_{3}$ (Fig. 3B); the rate-determining step is passage of the ring over the $\mathrm{CF}_{3}$ group from the catchment region to the $\mathrm{N}$-terminus. As ring-dethreading from $\mathbf{1 \cdot 3}$ is significantly slower than the 10 minutes required to complete an active template threading-and-stoppering reaction, in the presence of excess fuel $\mathbf{1 \cdot 3}$ collects additional rings through a continuous pumping process to give first [3]rotaxane 10 and then [4]rotaxane 7. Further iterations of the pumping cycle did not yield any [5]rotaxane, suggesting that the axle is already full in the [4]rotaxane.

For the rotaxane with two rings pumped onto the axle (10; Fig. 2B), two co-conformers are observed by ${ }^{1} \mathrm{H}$ NMR: car-tri-10, with one macrocycle residing over the carbamate group and the other in the catchment region, and tri-tri-10 with both macrocycles in the catchment region. The ratio of car-tri-10 to tri-tri-10 is 7:3 at $295 \mathrm{~K}$ in $\mathrm{C}_{6} \mathrm{D}_{5} \mathrm{CD}_{3}$. In contrast, only one co-conformer is observed for the [4]rotaxane, car-tri-tri-7 isomer (Fig. 2C), consistent with the results of the pumping studies that suggest that the axle of the [4]rotaxane is only long enough to accommodate three macrocycles. Extending the catchment region to include more triazole rings, or other groups that weakly stabilise the crown ether, is 
complicated by the need for the pump to be soluble in toluene, the optimal solvent ${ }^{28-30}$ for the active template reaction.

Considered together, these experimental results provide insight into the role and effect of the pump's power stroke. The ${ }^{1} \mathrm{H}$ NMR spectra (Fig. 2C) show that although the threaded ring is at lower energy in the catchment region than the carbamate region in the [2]rotaxane (car-4:tri-4 3:7; $295 \mathrm{~K}, \mathrm{C}_{6} \mathrm{D}_{5} \mathrm{CD}_{3}$ ), the [3]rotaxane is actually more thermodynamically stable when the additional ring is over the carbamate group rather than in the catchment region (car-tri-10:tri-tri-10 7:3; $295 \mathrm{~K}, \mathrm{C}_{6} \mathrm{D}_{5} \mathrm{CD}_{3}$ ). Steric considerations mean that [4]rotaxane can only be produced from active template threading of the tri-trico-conformer of $\mathbf{1} \cdot(\mathbf{3})_{2}$ (i.e. both rings in the catchment region of the open-ended pump). Therefore, pumping of the [3]rotaxane (which is a 7:3 mixture of car-tri-10:tri-tri-10) to the [4]rotaxane (7) can be viewed as proceeding: (i) car-tri-10 (the lowest energy co-conformer of the [3]rotaxane) to (ii) tri-tri-10 (a state that undergoes fast deblocking of the pump terminus) to (iii) $\mathbf{1 \bullet ( 3 )})_{2}$ (open-end pump available for active template threading, while the speed-bump inhibits dethreading of already captured rings) to (iv) car-tri-tri-7 (the [4]rotaxane); a sequence that actually involves an energetically uphill coconformational change (car-tri-10 to tri-tri-10)-a necessary, but endergonic, analogue of the power stroke that occurs to form the [2]- and [3]rotaxane. 
A
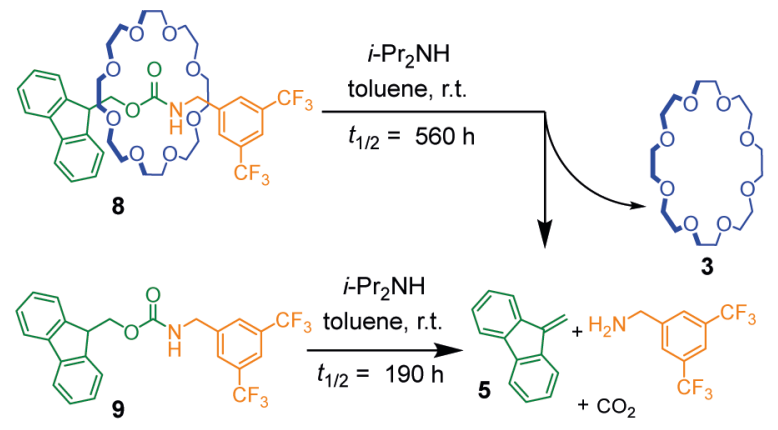

B

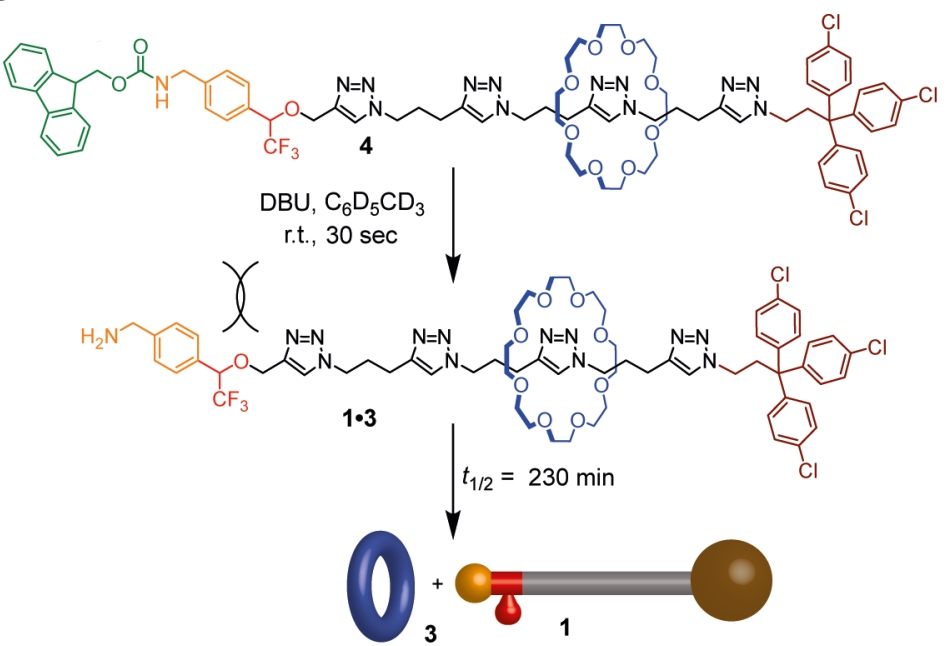

C

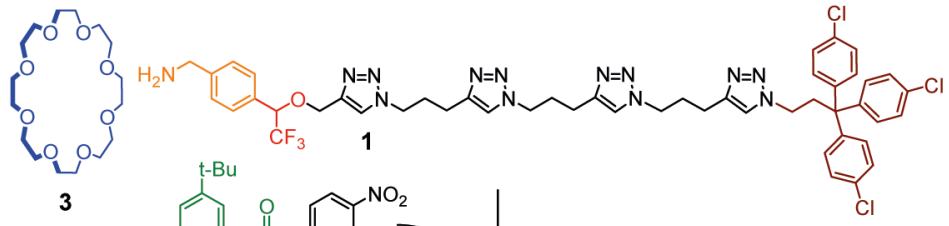

3<smiles>O=C(Oc1ccc([N+](=O)[O-])cc1)Oc1cc(Br)cc(Br)c1</smiles>

barrier attachment

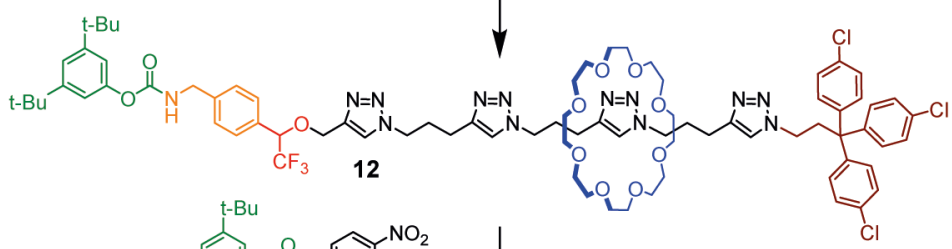

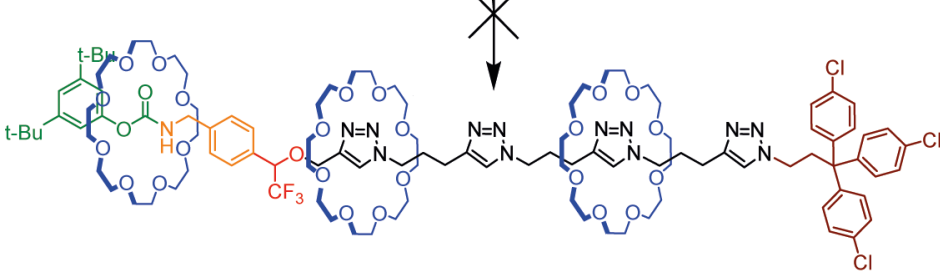

Figure 3. Fmoc removal, pseudorotaxane dethreading, and irreversible rotaxane formation experiments. (A) Reagents and conditions for Fmoc removal from model [2]rotaxane 8 and model noninterlocked thread 9: 8 or 9 (1 eq.) $i-\mathrm{Pr}_{2} \mathrm{NH}$ (10 eq.), toluene $(0.14 \mathrm{M})$, room temperature. (B) Reagents and conditions for Fmoc removal and subsequent dethreading: rotaxane 4, (1 eq.) DBU (50 eq.), $C_{6} D_{5} C D_{3}(21 \mathrm{mM})$, room temperature, 30 seconds, then diluted to $4.2 \mathrm{mM}$ with $C_{6} D_{5} C_{3}$ and monitored 
by ${ }^{1} \mathrm{H}$ NMR. (C) Reagents and conditions for formation of [2]rotaxane 12 using carbonate 11: pump 1 (1 eq.), 24-crown-8 3 (10 eq.), $i-\mathrm{Pr}_{2} \mathrm{NH}$ (15 eq.), toluene (0.2 M), reagent 11 (added continuously via syringe pump as a solution in toluene at a rate of 0.4 eq./h), room temperature, 16 hours. DBU, 1,8diazabicyclo(5.4.0)undec-7-ene; eq., equivalents.

Control experiments confirmed that there is no net displacement of 24-crown-8 rings from bulk solution onto 1 in the absence of fuel. At equilibrium, the amount of $\mathbf{1 \cdot 3}$ present in toluene is lower than the limits detectable by spectroscopy (see Supplementary Information). Furthermore, when an excess of an alternative carbonate, $\mathbf{1 1}$, was used in place of fuel $\mathbf{2}$, resulting in a $\mathrm{N}$-terminus carbamate that is not decomposed by base, [2]rotaxane 12 was the only threaded product isolated (Fig. 3C). This demonstrates that only one ring is pumped onto the axle by the consumption of each fuel molecule.

The pump can also operate if excess fuel and $i-\mathrm{Pr}_{2} \mathrm{NH}$ are present from the start, allowing multiple fuel cycles to occur autonomously to generate [n]rotaxanes until all of the fuel is consumed. However, in the presence of $i-\mathrm{Pr}_{2} \mathrm{NH}$ fuel $\mathbf{2}$ decomposes at a similar rate to the Fmoc-carbamate axle, so it is difficult to solubilise sufficient fuel at time-zero to generate significant amounts of [4]rotaxane. Accordingly, pump operation is more efficient with fuel continuously drip-fed to the pump rather than delivered in a single pulse. Treatment of pump 1 with 10 equivalents of 24-crown-8 (3), 15 equivalents of $i-\mathrm{Pr}_{2} \mathrm{NH}$ and 0.7 equivalents fuel (2) per hour for 16 hours generated [4]rotaxane 7, along with [2]rotaxane 4 and [3]rotaxane 10 (Fig. 4B). The threaded products are formed dissipatively ${ }^{34-37}$ under these operating conditions: Fmoc-carbamate decomposition continued for a further 19 days after ceasing the addition of fuel $\mathbf{2}$, causing $\mathbf{3}$ to be slowly released back into solution resulting in virtually all of the original amount of unthreaded axle and rings, $\mathbf{1}$ and $\mathbf{3}$, being recovered (see Supplementary Information). 

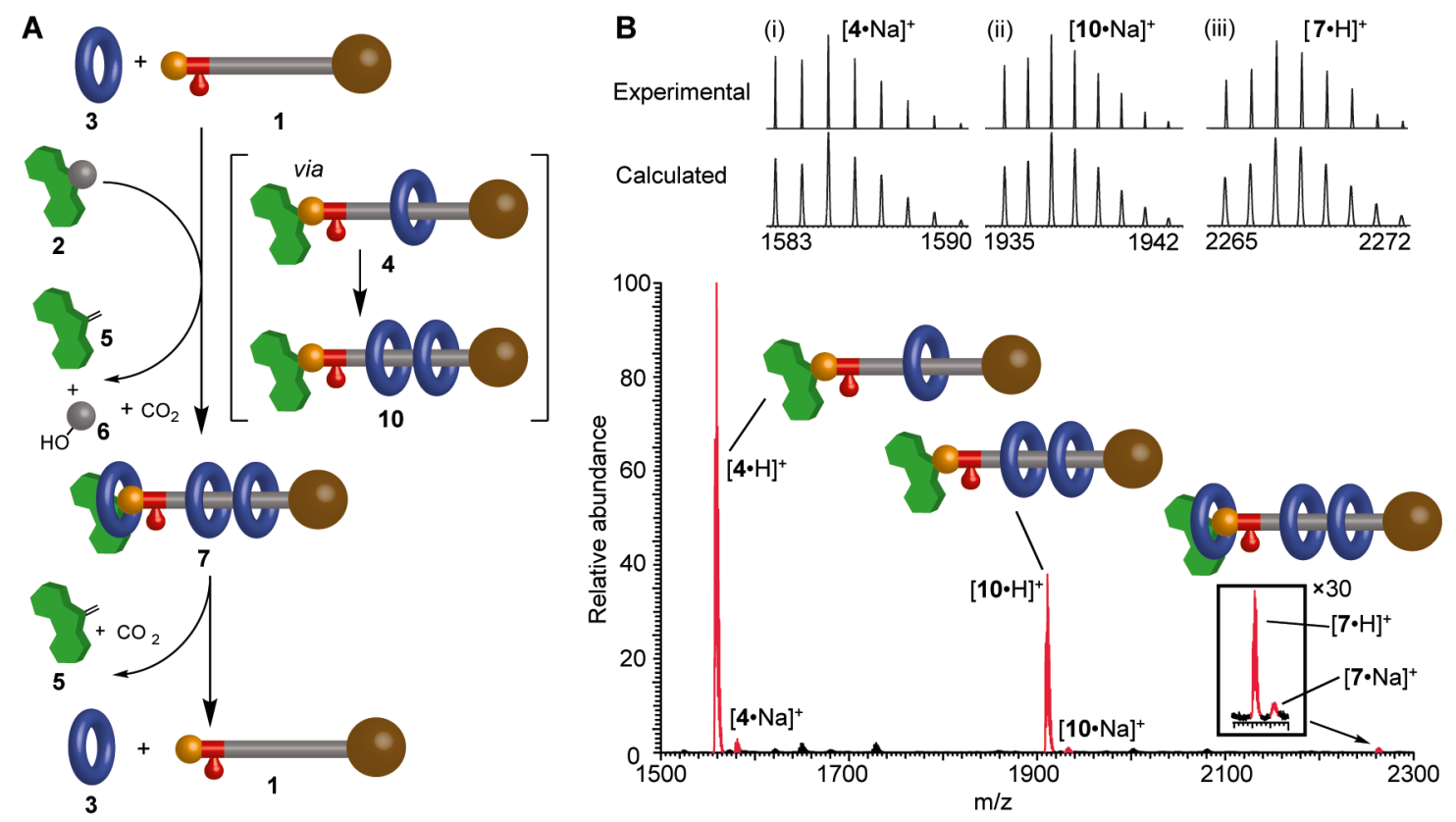

Figure 4. Out-of-equilibrium state produced by the operation of pump 1. (A) Reagents and conditions: pump 1 (1 eq.), 24-crown-8 3 (10 eq.), $i-\mathrm{Pr}_{2} \mathrm{NH}$ (15 eq.), toluene $(0.2 \mathrm{M})$, fuel 2 (added continuously via syringe pump as a solution in toluene at a rate of 0.7 eq./h), room temperature, 16 hours. After stopping the addition of fuel $\mathbf{2}$, half of the reaction mixture was left at room temperature for 19 days, regenerating the unthreaded components, $\mathbf{1}$ and $\mathbf{3}$. (B) Electrospray ionisation mass spectrum of the crude reaction mixture worked up just after stopping the addition of fuel $\mathbf{2}$. Signal intensity does not correspond to the amount of product formed. The signal corresponding to [4]rotaxane 7 is shown at x30 intensity. Isotopic patterns shown for $[4 \cdot \mathrm{Na}]^{+},[10 \cdot \mathrm{Na}]^{+}$and $[7 \cdot \mathrm{H}]^{+}$.

Synthetic chemically-fueled molecular pump 1 drives macrocycles from bulk solution into an organised, high energy, threaded assembly, and dissipatively maintains the out-of-equilibrium state for as long as unreacted chemical fuel remains. The pump uses a doubly kinetically-gated catalysis-driven information ratchet mechanism that is wholly artificial and minimalist in design, ${ }^{38}$ yet fundamentally analogous to that of biomolecular pumps. It is kinetic asymmetry in the act of threading under catalysis that drives the pumping away from equilibrium. ${ }^{20}$ The mechanism of pumping features a step which, for the first two rings, has the characteristics of a power stroke-'a viscoelastic, free-energy releasing, largeamplitude conformational change ${ }^{39,40}$-as the initially captured, high energy, crown ethers close to the carbamate group (e.g. car-4) relax to the catchment region (e.g. tri-4). However, the analogous coconformational change required to form the [4]rotaxane is an energetically uphill process. There is an ongoing debate concerning the role of power strokes in catalysis-driven biomolecular machines. ${ }^{39,41}$ In this catalysis-driven small-molecule pump the change of position of the ring(s) on the axle retards the rate of release of captured substrate. It does so irrespective of whether the co-conformational change 
on the axle is exergonic or not, although if this step is net energetically downhill (a power stroke) it is more effective. The mechanism of $\mathbf{1}$ is general (i.e. not restricted to particular substrates, functional groups or catalysts), and we anticipate that catalysis will play an increasingly important role in the design of artificial molecular machines ${ }^{20,42-48}$ and, thereby, ${ }^{21}$ the understanding of their biomolecular counterparts.

\section{References}

1. Skou, J. C. The Identification of the Sodium-Potassium Pump (Nobel Lecture). Angew. Chem. Int. Ed. 37, 2320-2328 (1998).

2. Lodish, H., Berk, A., Zipursky, S. L., Matsudaira, P., Baltimore, D. \& Darnell, J. 'Transport across Cell Membranes' in Molecular Cell Biology (W. H. Freeman, New York, 2000), vol. 4, chap. 15. 3. Du, D., Wang-Kan, X., Neuberger, A., van Veen, H. W., Pos, K. M., Piddock, L. J. V. \& Luisi, B. F. Multidrug efflux pumps: structure, function and regulation. Nat. Rev. Microbiol. 16, 523-539 (2018). 4. Qiu, Y., Feng, Y., Guo, Q.-H., Astumian, R. D. \& Stoddart, J. F. Pumps through the ages. Chem 6, 1952-1977 (2020).

5. Steinberg-Yfrach, G., Liddell, P. A., Hung, S.-C., Moore, A. L., Gust, D. \& Moore, T. A. Conversion of light energy to proton potential in liposomes by artificial photosynthetic reaction centres. Nature 385, 239-241 (1997).

6. Bennett, I. M., Farfano, H. M. V., Bogani, F., Primak, A., Liddell, P. A., Otero, L., Sereno, L., Silber, J. J., Moore, A. L., Moore, T. A. \& Gust, D. Active transport of $\mathrm{Ca}^{2+}$ by an artificial photosynthetic membrane. Nature 420, 398-401 (2002).

7. Bhosale, S., Sisson, A. L., Talukdar, P., Fürstenberg, A., Banerji, N., Vauthey, E., Bollot, G., Mareda, J., Röger, C., Würthner, F., Sakai, N. \& Matile, S. Photoproduction of proton gradients with T-stacked fluorophore scaffolds in lipid bilayers. Science 313, 84-86 (2006).

8. Serreli, V., Lee, C.-F., Kay, E. R. \& Leigh, D. A. A molecular information ratchet. Nature 445, 523527 (2007).

9. Baroncini, M., Silvi, S., Venturi, M. \& Credi, A. Photoactivated directionally controlled transit of a non-symmetric molecular axle through a macrocycle. Angew. Chem. Int. Ed. 51, 4223-4226 (2012). 10. Ragazzon, G., Baroncini, M., Silvi, S., Venturi, M. \& Credi, A. Light-powered autonomous and directional molecular motion of a dissipative self-assembling system. Nat. Nanotechnol. 10, 70-75 (2015).

11. Cheng, C., McGonigal, P. R., Schneebeli, S. T., Li, H., Vermeulen, N. A., Ke, C. \& Stoddart, J. F. An artificial molecular pump. Nat. Nanotechnol. 10, 547-553 (2015).

12. Pezzato, C., Nguyen, M. T., Cheng, C., Kim, D. J., Otley, M. T. \& Stoddart, J. F. An efficient artificial molecular pump. Tetrahedron 73, 4849-4857 (2017).

13. Erbas-Cakmak, S., Fielden, S. D. P., Karaca, U., Leigh, D. A., McTernan, C. T., Tetlow, D. J. \& Wilson, M. R. Rotary and linear molecular motors driven by pulses of a chemical fuel. Science 358, 340-343 (2017).

14. Pezzato, C., Nguyen, M. T., Kim, D. J., Anamimoghadam, O., Mosca, L. \& Stoddart, J. F. Controlling dual molecular pumps electrochemically. Angew. Chem. Int. Ed 57, 9325-9329 (2018). 15. Quu, Y., Zhang, L., Pezzato, C., Feng, Y., Li, W., Nguyen, M. T., Cheng, C., Shen, D., Guo, Q.-H., Shi, Y., Cai, K., Alsubaie, F. M., Astumian, R. D. \& Stoddart, J. F. A molecular dual pump. J. Am. Chem. Soc. 141, 17472-17476 (2019).

16. Qiu, Y., Song, B., Pezzato, C., Shen, D., Liu, W., Zhang, L., Feng, Y., Guo, Q.-H., Cai, K., Li, W., Chen, H., Nguyen, M. T., Shi, Y., Cheng, C., Astumian, R. D., Li, X. \& Stoddart, J. F. A precise polyrotaxane synthesizer. Science 368, 1247-1253 (2020).

17. Astumian, R. D. \& Bier, M. Mechanochemical coupling of the motion of molecular motors to ATP hydrolysis. Biophys. J. 70, 637-653 (1996). 
18. Kay, E. R., Leigh, D. A. \& Zerbetto, F. Synthetic molecular motors and mechanical machines. Angew. Chem. Int. Ed. 46, 72-191 (2007).

19. Astumian, R. D. Design principles for Brownian molecular machines: how to swim in molasses and walk in a hurricane. Phys. Chem. Chem. Phys. 9, 5067-5083 (2007).

20. Astumian, R. D. Kinetic asymmetry allows macromolecular catalysts to drive an information ratchet. Nat. Commun. 10, 3837 (2019).

21. Astumian, R. D. How molecular motors work - insights from the molecular machinist's toolbox: the Nobel prize in Chemistry 2016. Chem. Sci. 8, 840-845 (2017).

22. Pezzato, C., Cheng, C., Stoddart, J. F. \& Astumian, R. D. Mastering the non-equilibrium assembly and operation of molecular machines. Chem. Soc. Rev. 46, 5491-5507 (2017).

23. Kassem, S., van Leeuwen, T., Lubbe, A. S., Wilson, M. R., Feringa, B. L. \& Leigh, D. A. Artificial molecular motors. Chem. Soc. Rev. 46, 2592-2621 (2017).

24. Wang, Q., Chen, D. \& Tian, H. Artificial molecular machines that can perform work. Sci. China Chem. 61, 1261-1273 (2018).

25. Findlay, J. A. \& Crowley, J. D. Functional nanomachines: recent advances in synthetic molecular machinery. Tetrahedron Lett. 59, 334-346 (2018).

26. Coutrot, $\mathrm{F}$. A focus on triazolium as a multipurpose molecular station for $\mathrm{pH}$-sensitive interlocked crown-ether-based molecular machines. ChemistryOpen 4, 556-576 (2015).

27. Zheng, H., Zhou, W., Lv, J., Yin, X., Li, Y., Liu, H. \& Li, Y. A dual-response [2]rotaxane based on a 1,2,3-triazole ring as a novel recognition station. Chem. Eur. J. 15, 13253-13262 (2009).

28. Fielden, S. D. P., Leigh, D. A., McTernan, C. T., Pérez-Saavedra, B. \& Vitorica-Yrezabal, I. J. Spontaneous assembly of rotaxanes from a primary amine, crown ether and electrophile. J. Am. Chem. Soc. 140, 6049-6052 (2018).

29. Tian, C., Fielden, S. D. P., Whitehead, G. F. S., Vitorica-Yrezabal, I. J. \& Leigh, D. A. Weak functional group interactions revealed through metal-free active template rotaxane synthesis. Nat. Commun. 11, 744 (2020).

30. Tian, C., Fielden, S. D. P., Pérez-Saavedra, B., Vitorica-Yrezabal, I. J. \& Leigh, D. A. Single-step enantioselective synthesis of mechanically planar chiral [2]rotaxanes using a chiral leaving group strategy. J. Am. Chem. Soc. 142, 9803-9808 (2020).

31. Denis, M. \& Goldup, S. M. The active template approach to interlocked molecules: Principles, progress and applications. Nat. Rev. Chem. 1, 0061 (2017).

32. Wilson, M. R., Solá, J., Carlone, A., Goldup, S. M., Lebrasseur, N. \& Leigh, D. A. An autonomous chemically fuelled small-molecule motor. Nature 534, 235-240 (2016).

33. Fyfe, M. C. T., Glink, P. T., Menzer, S., Stoddart, J. F., White, A. J. P. \& Williams, D. J. Anion assisted self-assembly. Angew. Chem., Int. Ed. Engl. 36, 2068-2070 (1997).

34. della Sala, F., Neri, S., Maiti, S., Chen, J. L.-Y. \& Prins, L. J. Transient self-assembly of molecular nanostructures driven by chemical fuels. Curr. Opin. Biotech. 46, 27-33 (2017).

35. van Rossum, S. A. P., Tena-Solsona, M., van Esch, J. H., Eelkema, R. \& Boekhoven, J.

Dissipative out-of-equilibrium assembly of man-made supramolecular materials. Chem. Soc. Rev. 46, 5519-5535 (2017).

36. Ragazzon, G. \& Prins, L. J. Energy consumption in chemical fuel-driven self-assembly. Nat.

Nanotechnol. 13, 882-889 (2018).

37. Rieß, B., Grötsch, R. \& Boekhoven, J. The design of dissipative molecular assemblies driven by chemical reaction cycles. Chem 6, 552-578 (2020).

38. Borsley, S., Leigh, D. A. \& Roberts, B. M. W. A doubly kinetically-gated information ratchet autonomously driven by carbodiimide hydration. J. Am. Chem. Soc. 143, 4414-4420 (2021). 39. Astumian, R. D. Irrelevance of the power stroke for the directionality, stopping force, and optimal efficiency of chemically driven molecular machines. Biophys. J. 108, 291-303 (2015).

40. Howard, J. Protein power strokes. Curr. Biol. 16, R517-R519 (2006).

41. Hwang, W. \& Karplus, M. Structural basis for power stroke vs. Brownian ratchet mechanisms of motor proteins. Proc. Natl. Acad. Sci. USA 116, 19777-19785 (2019). 
42. van Dijk, L., Tilby, M. J., Szpera, R., Smith, O. A., Bunce, H. A. P. \& Fletcher, S. P. Molecular machines for catalysis. Nat. Rev. Chem. 2, 0117 (2018).

43. Zhang, L., Marcos, V. \& Leigh, D. A. Molecular machines with bio-inspired mechanisms. Proc. Natl. Acad. Sci. USA 115, 9397-9404 (2018).

44. Biagini, C., Fielden, S. D. P., Leigh, D. A., Schaufelberger, F., Di Stefano, S. \& Thomas, D. Dissipative catalysis with a molecular machine. Angew. Chem. Int. Ed. 58, 9876-9880 (2019).

45. Astumian, R. D., Pezzato, C., Feng, Y., Qiu, Y., McGonigal, P. R., Cheng, C. \& Stoddart, J. F. Non-equilibrium kinetics and trajectory thermodynamics of synthetic molecular pumps. Mater. Chem. 4, 1304-1314 (2020).

46. Heard, A. W. \& Goldup, S. M. Simplicity in the design, operation and applications of mechanically interlocked molecular machines. ACS Cent. Sci. 6, 117-128 (2020).

47. Aprahamian, I. The future of molecular machines. ACS Cent. Sci. 6, 347-358 (2020).

48. Moulin, E., Faour, L., Carmona-Vargas, C. C. \& Giuseppone, N. From molecular machines to stimuli-responsive materials. Adv. Mater. 32, e1906036 (2020).

49. Lee, J., Yu, E., Park, J., Ryu, I., Shin, D. \& Gong, Y. Solid-phase synthesis of 7-arylbenzo[b][1,4]oxazin-3(4H)-one derivatives on a BOMBA resin utilizing the Smiles rearrangement. Bull. Korean Chem. Soc. 30, 1325-1330 (2009).

50. Hunter, C. A. Quantifying intermolecular interactions: guidelines for the molecular recognition toolbox. Angew. Chem. Int. Ed. 43, 5310-5324 (2004).

\section{Methods}

General methods for the operation of the pump with continuous fuel addition: To a solution of 1 (5.8 mg, $5.9 \mu \mathrm{mol}, 1$ eq.) and $3\left(21 \mathrm{mg}, 60 \mu \mathrm{mol}, 10\right.$ eq.) in dry toluene $(27 \mu \mathrm{L})$ was added $i-\operatorname{Pr}_{2} \mathrm{NH}(12$ $\mu \mathrm{L}, 88 \mu \mathrm{mol}, 15$ eq.). A solution of 2 ( $23 \mathrm{mg}, 63 \mu \mathrm{mol}, 11$ eq.) in toluene (133 $\mu \mathrm{L}$ total volume) was continuously added via syringe pump at r.t. for $16 \mathrm{~h}$. An aliquot (ca. $2 \mu \mathrm{L})$ of the mixture was diluted with $\mathrm{CDCl}_{3}(500 \mu \mathrm{L})$ and immediately analysed by ${ }^{1} \mathrm{H}$ NMR $(600 \mathrm{MHz}, 298 \mathrm{~K})$. To the reaction mixture was added $\mathrm{CF}_{3} \mathrm{COOH}(10 \mu \mathrm{L})$ and saturated aqueous $\mathrm{NH}_{4} \mathrm{Cl}(5 \mathrm{~mL})$. The mixture was extracted with $\mathrm{CH}_{2} \mathrm{Cl}_{2}(3 \times 5 \mathrm{~mL})$. The combined organic extracts were concentrated under reduced pressure. The residue was analysed by ESI-MS, which indicated the presence of [2] rotaxane 4, [3]rotaxane 10 and [4]rotaxane 7.

\section{Acknowledgements}

We thank the Engineering and Physical Sciences Research Council (EPSRC; EP/P027067/1) and the European Research Council (ERC; Advanced Grant no. 786630) for funding. We also thank the University of Manchester, Department of Chemistry Services for mass spectrometry. D.A.L. is a Royal Society Research Professor.

\section{Author contributions}

S.A. and S.D.P.F. carried out the synthesis and characterisation studies. D.A.L. directed the research. All authors contributed to the analysis of the results and the writing of the manuscript.

\section{Competing Interests statement}

The authors declare no competing interests.

Additional information: Supplementary Information is available for this paper. Correspondence and requests for materials should be addressed to David A. Leigh. Reprints and permissions information is available at www.nature.com/reprints.

\section{Data availability}

The data that support the findings of this study are available within the paper and its Supplementary Information, or are available from the Mendeley data repository (https://data.mendeley.com/) under doi xxxxxx. 